Investigaciones Feministas

ISSN-e: 2171-6080

http://dx.doi.org/10.5209/INFE.52284

\title{
Resistencias femeninas. Arte contemporáneo regional desde una perspectiva de género
}

\author{
Andrea Geat ${ }^{1}$
}

Recibido: abril 2016 / Evaluado: febrero 2017 / Aceptado: abril 2016

Resumen. El presente artículo explora la capacidad de la teoría de género para abordar la producción artística de mujeres de la ciudad de Resistencia (Chaco, Argentina) con el objetivo de analizar sus trabajos a partir de nociones, conceptos y problemáticas que han podido leerse en sus obras. La selección corresponde a producciones de tres autoras que viven y trabajan actualmente en Resistencia y que han planteado a través de sus obras la sexualidad femenina como temática para la problematización de ideas por medio de su compromiso estético y personal. Con el fin de reflexionar sobre la creación estética a partir del tópico de la/s sexualidad/es en diferentes expresiones plásticas, la descripción iconográfica, el análisis de las obras y la lectura en clave de género confluyen en este trabajo para poner en cuestión categorías y conceptos abordados en las obras como el trabajo doméstico, los estereotipos de mujeres, la maternidad, ciertos tabúes que persisten en la cultura, modos de violencia, el deseo y el goce sexual femenino.

Palabras clave: Arte; feminismo; deseo; sexualidad; feminidad.

\section{[en] Female resistance. Regional contemporary art from a gender perspective}

\begin{abstract}
This article explores the capacity of gender theory to address the artistic production of women in the city of Resistencia (Chaco, Argentina) in order to analyze their work from notions, concepts and issues that have been read in their works. The selection corresponds to productions of three authors who live and work currently in Resistencia and who have raised, by their works on female sexuality as a theme, the questioning of ideas through their aesthetic and personal commitment. In order to reflect on aesthetic creation from the topic of sexuality in different artistic expressions, the iconographic description, analysis of works and reading in terms of gender converge in this paper and allow to question categories and concepts herein addressed such as domestic work, stereotypes of women, motherhood, certain taboos that persist in culture, ways of violence, desire and female sexual enjoyment.
\end{abstract}

Key words: Art; feminism; desire; sexuality; feminity.

Sumario. 1. Introducción. 2. Mujeres, Arte y Cuerpos. 3. Tres artistas de Resistencia(s). 4. La condición femenina. 5. $\mathrm{La}$ (s) sexualidad(es) en escena. 6. Sobre la belleza de lo siniestro. 7. Observaciones finales. Bibliografía.

Cómo citar: Andrea Geat (2017): "Resistencias femeninas. Arte contemporáneo regional desde una perspectiva de género", en Revista de Investigaciones Feministas 8 (1), 283-298.

\footnotetext{
1 Universidad Nacional del Nordeste / Consejo Nacional de Investigaciones Científicas y Técnicas (Argentina). andygeat@gmail.com
} 


\section{Introducción}

Desde la última década del siglo pasado, los estudios históricos y las corrientes revisionistas en Latinoamérica han dado cuenta de una profunda exploración crítica tanto de sus contenidos como de las metodologías y los enfoques analíticos utilizados. Los Estudios Visuales o de la Cultura Visual han sido en las últimas décadas uno de los procesos que permitieron poner en diálogo a la historia del arte con otras disciplinas, ampliando sus objetos de estudio más allá de las restricciones que imponía el canon. En Argentina esto se tradujo en la inclusión de actores artísticos que habían sido omitidos con anterioridad de la historia oficial por centrar su atención en la capital porteña, que establecía "La historia del arte argentino" desde y hacia Buenos Aires. Por otra parte, también comenzaron a sistematizarse estudios sobre el arte a partir de nuevas problemáticas y prácticas artísticas que fueron introduciéndose como "otras historias" o "nuevas historias" del arte, en donde el papel del historiador del arte ha asumido un rol esencial como revisionista. (Gutiérrez Viñuales, 2005). Entre las nuevas prácticas que estas renovaciones inscribieron, la investigación en historia del arte supone desde entonces cuestionar categorías y problematizar analíticamente a partir de ejes conceptuales. Por un lado, se considera que este nuevo enfoque ha contribuido a la valoración de artistas y regiones de la periferia pero además, ha posibilitado la instauración de la idea de que la(s) historia(s) del arte constituye(n) un campo en constante transformación que debe ser estudiado en relación a los cambios sociales e intelectuales del presente. Entendemos que estudiar el arte contemporáneo ya no consiste en reunir biografías de artistas, ordenar sus "períodos plásticos" cronológicamente o de sistematizar información de acuerdo a líneas estéticas, sino poner en discusión modos de producción y problemáticas abordadas por las y los artistas en función de las discusiones o debates presentes en la sociedad.

Con el aporte de la teoría feminista como enfoque analítico para el estudio y como marco adecuado para la comprensión de algunos fenómenos de índole estético, este trabajo consiste en una lectura analítica de obras a partir del método iconográfico/iconológico (Panofsky, 1987). Nos interesa reflexionar respecto de la presencia de enunciaciones de género que podemos advertir en un conjunto de obras de artistas del Nordeste argentino (NEA) con quienes trabajamos en entrevistas y discutiendo sobre sus producciones en talleres.

Consideramos que el estudio sobre las artes visuales realizado sobre obras de artistas mujeres de Resistencia, constituyen un modo de concebir el papel de la historia y la crítica de arte en conexión con las corrientes de pensamiento contemporáneo que posibilitan la construcción de una historia de las artes con perspectiva crítica, teniendo en cuenta no solo las producciones, sino también sus voces y contextos productivos.

El arte feminista desde los setenta a la actualidad ha estado atravesado por problemáticas como la sexualidad, el cuerpo y la subjetividad, así como también dimensiones políticas, sociales, culturales, ideológicas y sobre "el lugar de la mujer" en la sociedad. La apropiación de la imagen del cuerpo de las artistas seleccionadas para este trabajo, ha transitado problemáticas que hacen referencia a la/s sexualidad/es femeninas para expresar "malestares de género" (Izquierdo, 1998) pero también poner atención en la genitalidad y en manifestarse sobre cuestiones políticas respecto del cuerpo. 
Este trabajo presenta en primera instancia un enfoque general acerca de la participación femenina en las artes visuales y su vinculación con la crítica feminista y por último, la presentación de tres artistas que viven y trabajan en la ciudad de Resistencia (Chaco, Argentina) con el objetivo de dar a conocer su arte, intenciones y gestos de discursividad feminista.

\section{Mujeres, Arte y Cuerpos}

Pensar a las artes visuales en relación con el género de sus autoras constituye una práctica reciente en Latinoamérica, pero que tiene sus raíces en los revisionismos historiográficos y críticos influidos por los estudios culturales, postcoloniales y del feminismo de las últimas décadas del siglo pasado.

En el campo del estudio sobre las artes, Linda Nochlin (2007) inauguró el debate en 1971 al preguntarse "¿Por qué no han existido grandes artistas mujeres?". Su pregunta no se dirigía a "rescatar" mujeres olvidadas u omitidas — como algunos primeros estudios feministas se esforzaron por encontrar- ni a que los historiadores o historiadoras indagaran si efectivamente habían existido. Lo que Nochlin había advertido a inicios de los setenta, es que en la Historia del Arte no había figuras femeninas equivalentes al "genio" varón-blanco-occidental-burgués (Mayayo, 2007:66-72). Los límites patriarcales puestos al acceso a la educación y a la formación artística de las mujeres, la división sexual del trabajo o los obstáculos familiares fueron las principales causas que limitaron históricamente a que las mujeres pudieran desarrollar una profesionalización artística. Pero había además, cuestiones menos obvias y eso fue lo que Nochlin proponía desde su interrogante.

A mediados de los ochenta en Estados Unidos, teóricas comprometidas con la crítica feminista como Griselda Pollock y Rozsika Parker instalaron debates en torno al cuerpo, la mirada, el canon o la diferenciación y plantearon una serie de discusiones sobre la representación y su vinculación con el género de las artistas. En consonancia, artistas como Judy Chicago, Miriam Schapiro y Barbara Kruger hicieron de sus obras de arte "el campo de batalla" en la misma dirección. El intercambio entre artistas e intelectuales derivó en profundos análisis y críticas sobre las obras, pero también sobre las condiciones de producción, los modos de legitimación, los circuitos del arte y un sinnúmero de temas relativos a estos procesos.

En Latinoamérica estas ideas tardaron un tiempo en germinar. En los años ochenta y noventa se organizaron exposiciones de artistas mujeres que no solo respondían a reivindicaciones feministas sino que se inscribían en un contexto mayor de descompresión postdictadura. Sobre el debate y las prácticas tendientes a focalizar en lo concerniente a arte y género, "las exposiciones de mujeres tuvieron el carácter político de construir un lugar de visibilidad que luego fue desechado bajo el mote de gueto." (Giunta 2011: 25).

Específicamente en Buenos Aires, las investigaciones sobre las artes de los ochenta y noventa de María Laura Rosa (2014) se centraron en la reconstrucción histórica de intervenciones feministas que comenzaron a aparecer intermitente y tardíamente en la Argentina, debido a situaciones sociales y políticas casi siempre desfavorables para la libertad de expresión.

A cuarenta años de la pregunta inaugural de Nochlin, en América Latina no hay dudas de que a través de un proceso lento y paulatino, las mujeres han podido ingre- 
sar a la escena artística y logrado un progresivo aumento en número de participación. Sin embargo en sus obras aún pueden leerse ciertas demandas que se expresan hacia ideas hegemónicas presentes en la cultura.

Frente a este clima en parte (o en teoría) favorable para el colectivo femenino pasada ya la primera década del siglo XXI, es probable que haya quienes se pregunten si aún tiene sentido analizar los rasgos subjetivos en las obras de arte en vinculación con el género de sus autoras, y precisamente tal relación es una de las principales causas de su estudio, ya que en "los estudios de género se hace hincapié no directamente en el objeto o sujeto de investigación sino en la categoría que se emplea como herramienta de análisis de los fenómenos, subrayando el carácter de la construcción cultural de lo femenino y masculino" (Bach, Gianella, Femenías, Roulet y Santa Cruz, 1994:23) y las representaciones sometidas a análisis, son el resultado de un sistema de relaciones sociales, políticas e ideológicas que las configuran.

Hacia finales de la década del setenta, algunas artistas norteamericanas comenzaron a ser conscientes de "(...) la artificialidad y del poder represivo de lo que se denominará la construcción social del género" (Prada, 2000:150) y sus trabajos estéticos comenzaron a evidenciar el "yo" dañado por la imposición de los roles sociales que históricamente se le habían asignado a las mujeres. Las artistas supusieron que estas obras podrían servir de base para la construcción de una nueva identidad femenina. Sin embargo — como expresa Prada - encontraron una intensa resistencia dentro de las corrientes feministas que consideraban reduccionista creer que la esencia femenina residía en algún lugar del cuerpo. Hilary Robinson (1995) entiende que estas preocupaciones de hallar lo femenino en la corporalidad o a través de la experiencia corporal pueden percibirse como cuestiones de origen cultural y social debido a que si bien la experiencia de lo femenino es la experiencia del cuerpo, lo femenino no le pertenece esencialmente.

Ante este panorama y en el encuentro con obras de esta naturaleza en el campo artístico local y de correspondencias entre problemáticas planteadas, surgen diferentes interrogantes: ¿En qué sentido(s) nuestras artistas toman el cuerpo o su representación como recurso para la expresión estética vinculada a su(s) experiencias(s) como mujeres? ¿Por qué en condiciones similares a las de hace casi medio siglo? Acordamos con Robinson en su idea que podría ser allí donde tenga lugar la maniobra de construcción de una representación para su inteligibilidad. Sin embargo hay muchas otras cuestiones independientes de la adhesión a algún tipo de ideología feminista (sea ésta manifiesta o no).

Entre las construcciones socioculturales e históricas del ser-mujer "los modelos" han ido variando de acuerdo a las culturas regionales, ya que el género (sea este masculino o femenino) se codifica de acuerdo a las estructuras de poder de una sociedad y en una época determinada. Las representaciones de las mujeres tanto en el espacio artístico como en otros, se ordenan significativamente diferente a las producidas por varones y cuando este ordenamiento posee conciencia de género, la representación varía precisamente porque hay una perspectiva que no pretende ser absoluta, sino parcial y subjetiva.

Para analizar críticamente los discursos y representaciones sobre sexualidad y corporalidad en las artes visuales, no se debe simplemente valorarlos o cuestionarlos, es necesario además evaluar los contextos en los cuales éstos aparecen e inte- 
rrogar sobre las relaciones de poder, las configuraciones identitarias de sus autoras y hacia qué interlocutores y/o interlocutoras están dirigidos, ese es el objetivo que persigue esta propuesta.

\section{Tres artistas de Resistencia(s)}

Resistencia es una de las ciudades más jóvenes de la Argentina. Está ubicada en la Región Nordeste y con fecha de fundación oficial el 2 de febrero de 1878, constituye una de las últimas ciudades capitales de provincia fundadas en territorio argentino. Pertenece al departamento San Fernando, junto con las localidades Barranqueras, Fontana, Puerto Vilelas y Basail que en su conjunto poseen poco más de 385.000 habitantes de acuerdo al censo (2010). Resistencia ha logrado ser reconocida a nivel nacional por su intensa actividad cultural. En 2006 ha sido nombrada "Capital Nacional de las Esculturas" por el Senado Nacional en reconocimiento a las más de quinientas obras escultóricas que ostenta en sus espacios públicos. En las últimas décadas se ha consolidado como un importante centro de producción artística a partir de las Bienales Internacionales de Escultura, pero también por la vasta producción artística en todas sus expresiones que allí tienen lugar.

La elección de obras de artistas mujeres para su registro y análisis propone no solo una perspectiva ginocrítica, basada en su determinación como sujetos femeninos; además pretende la apertura de un espacio de visibilización y debate de producciones contemporáneas del circuito artístico local. En las obras seleccionadas aquí, se han percibido preocupaciones en torno a ideas de cómo vivencian las autoras el ser mujer. La experiencia corporal condicionada por el género forma parte tanto de sus discursos estéticos como verbales. Experiencias biológicas como la menstruación, el embarazo y el goce sexual son asuntos constantes entre sus representaciones, como también lo son los roles de género que las conduce a una problemática común: sus preocupaciones tanto en su vida social, económica y cultural.

María Victoria González (1957), Elizabeth "Licha" Bernal (1966) y Jarumi Nishishinya (1979) son artistas que han intentado profesionalizar su trabajo artístico en Resistencia, aunque ésta no haya sido la profesión principal de ninguna de ellas.

Las tres comparten experiencias comunes como artistas; como la de haberse formado en instituciones en las cuales sus educadores eran mayoritariamente (por no decir exclusivamente) varones pero las estudiantes mujeres constituían la mayoría de la población estudiantil. Una de las dificultades a la que se enfrentaron durante su formación fue la ausencia de modelos femeninos: mujeres artistas profesionales con quienes identificarse. Aunque la actividad artística de mujeres en la Argentina y en la ciudad de Resistencia comenzaba a consolidarse ya desde los sesenta a través de algunas personalidades influyentes, constituían una minoría en su legitimación y circulación efectiva el circuito cultural. Otra de las dificultades, fue (y sigue siendo) el desfavorable contexto para la producción. La dedicación a las artes visuales significó para ellas en muchos momentos un desafío, debiendo resignar tiempo de estudio, trabajo, de demandas familiares o descanso. Lo que las convirtió en muchas ocasiones, en artistas con vocación de resistencia: Resistir el cansancio producto de las horas de trabajo, las crisis económicas, las demandas familiares, los compromisos profesionales y hasta las "propias culpas", para poder producir. 
Resistir para producir obra, se convierte en significativo cuando la subjetividad está siendo atravesada por un gran número de factores que instan a abandonar un oficio en el que ellas no han podido aun profesionalizarse; es decir, vivir del arte y no para él. Ver y saber de sus resistencias, enfocó nuestro interés en estas creadoras que no buscan el mero reconocimiento artístico sino que intentan — desde su artela construcción de puentes para abrir caminos a nuevos modos de actuar y pensar en las mujeres que somos y las sexualidades que vivimos.

\section{La condición femenina}

María Victoria González es profesora de pintura y grabado, pero se autodefine como artista plástica. Durante una instalación desarrollada en 2011 titulada "La condición femenina" logró sintetizar ideas desarrolladas en distintas instancias de sus obras. Su producción se caracteriza por la referencia constante a los procesos vitales tanto humanos como de otros seres vivos. Para representarlos utiliza semillas y recursos vegetales que recolecta de la naturaleza y posteriormente manipula para metaforizar y construir analogías. González entiende que sus obras surgen de ideas vinculadas a su mundo cotidiano sumadas al interés personal en aspectos biológicos como el paso del tiempo, las enfermedades e instancias necrófilas de los órganos.

En la serie "La condición femenina" elegida para este trabajo, el cuerpo femenino es el protagonista principal: Los órganos, la sangre menstrual y la representación de otros fluidos ponen en circulación un conjunto de ideas que giran en torno a temas que poco tienen que ver a la intimidad con la que históricamente se ha asociado a estos procesos. La obra completa es una instalación, que consta de tres obras que se distribuyeron en los espacios de circulación de la Facultad de Artes, Diseño y Ciencias de la Cultura de la Universidad Nacional del Nordeste.

Habituada al trabajo de grabado, en sus obras de los años 2010 y 2011 las tintas y la prensa pasaron a segundo plano porque según su autora, La condición femenina debía exceder los formatos habituales y precisaba materiales y técnicas más afines a sus necesidades discursivas. El grabado sigue presente como técnica pero aplicada a las telas que se utilizaron para la confección de las obras, que son básicamente objetos escultóricos textiles. Tras varios años de dedicación a técnicas tradicionales de grabado y a la exploración en modos propios de composición, que el grabado perdiera protagonismo como lenguaje principal de su obra coincidió con cambios personales que modificaron sus preocupaciones, sus tiempos y con ellos las reflexiones y resultados de su trabajo.

La instalación está conformada por tres obras, que de acuerdo al recorrido y ubicación del guión de la exposición, la primera consiste en una semiesfera blanca de tela, de textura y trama similar a la de un almohadón que emerge del enérgico tono rojo de la pared. De su reverso brotan hebras de estopa blanca (un material derivado del algodón utilizado para la limpieza doméstica, en la actualidad casi en desuso). Una segunda obra se encuentra contiguamente, a un costado de la escalera, sobre una superficie roja. La artista dispuso allí un textil realizado de fibras de algodón y de forma semejante a un centro de mesa. La forma, el color y la trama del tejido generan referencia a tejidos humanos y formaciones quísticas. Por último, al encuentro con la escalera, nos encontramos con las mismas hebras de algodón de la estopa, pero en este caso de saturada tonalidad roja que salen de un objeto textil ubicado sobre la esquina del primer descanso y que seccionado longitudinalmente en su eje central refiere claramente a una vagina. 
En función de asociar el título de la obra, las formas orgánicas y los colores la materialidad y la vinculación de las obras entre sí, el conjunto de obras refiere a óvulos, órganos sexuales, sangre y otros fluidos corporales. La artista acude al tema de la mujer que sangra en sus "días malos" para exponer dicotomías sobre la mujer históricamente tabuada, recordando tópicos que formaron a las mujeres durante siglos y ordenaban que debían ser escondidas durante su período menstrual.

"El conjunto de obras que componen la condición femenina aborda aspectos físicos, fisiológicos y culturales que se entretejen en torno a la fecundidad: el ciclo menstrual, la ovulación, el momento de fertilización del óvulo, (...) que ponen en escena los "días malos" de cada mujer, cualificación inmanente en el imaginario colectivo, causando rechazo, asco y malestar'."

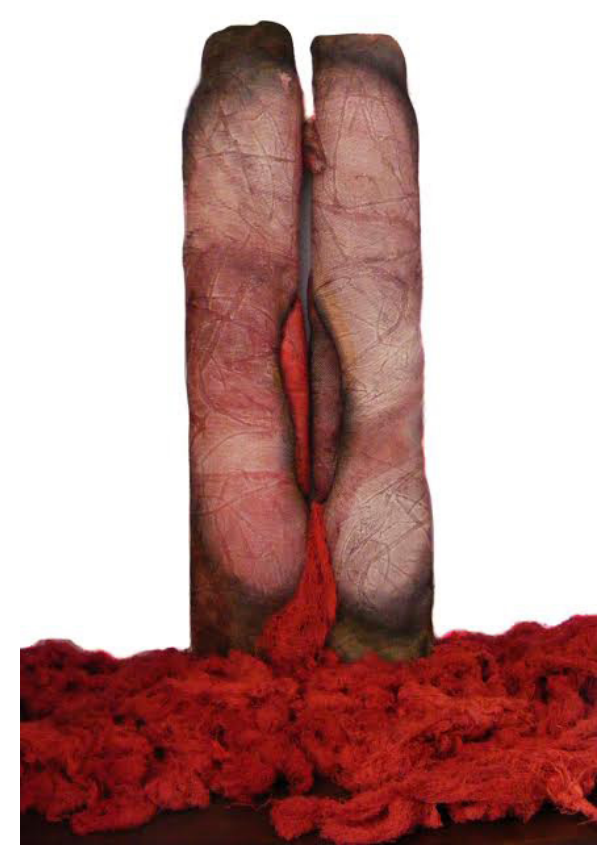

Figura. 1. María Victoria González "La condición femenina" (2011) Objeto/ Instalación. Fotografía de la artista.

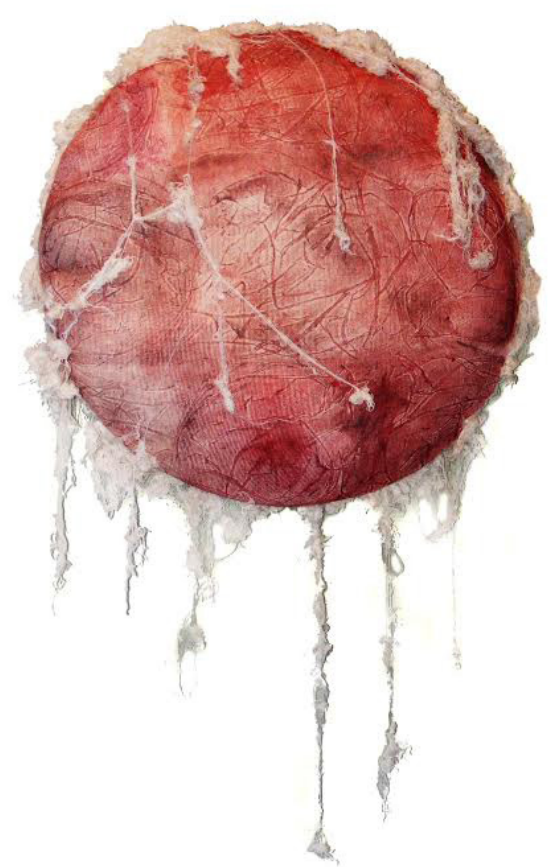

Figura. 2. María Victoria González "La condición femenina" (2011) Objeto/ Instalación. Fotografía de la artista.

La experiencia biológica femenina en el arte en ocasiones es erróneamente asociada a "la naturaleza de las mujeres" en concepciones esencialistas, pero la utilización de imágenes como la sangre menstrual, las imágenes clitóricas o el embarazo son de utilidad para las artistas en tanto están ausentes en el arte masculino.

2 Texto de la artista sobre su propia obra incluido en el catálogo de la exposición Chaco Art Boomerang-Programa Federal para las Artes, Universidad Nacional del Nordeste, Resistencia, 2011. 
El cuerpo es un medio que utiliza González para elaborar desde allí las representaciones que le permiten percibir críticamente la condición femenina en la actualidad. El seguimiento de su obra y la correlación con producciones anteriores, deja ver que a través de sus preocupaciones biológicas, hay una intención general de hacer foco sobre el lugar de la figura femenina en la familia, en la sociedad y en la cultura. Imposiciones, restricciones y deberes asignados a las mujeres que dan por resultado obras que intentan revelar algunas ideas respecto a relaciones sociales asimétricas. La referencia a la experiencia de lo biológico y sus asociaciones a los tabúes y ocultamientos, a lo público y lo privado, a lo íntimo y al trabajo de limpieza doméstico constituye una postura crítica de la artista hacia mandatos sociales que han condicionado a las mujeres solo por el hecho de haber nacido bajo tal condición.

La artista asume que hay una intención de hacer visibles los procesos vitales que por un lado, son biológicos. Y que la necesidad de focalizar sobre ellos para la obra artística tiene que ver con vinculaciones a lo cultural. De modo que a través de alusiones al cuerpo femenino, despliega en su obra dicotomías sobre lo adquirido y lo conquistado, lo impuesto y lo aprendido, lo deseado y lo posible para las mujeres de principios del Siglo XXI. Recordar los tabúes, tiene que ver en el caso de González, con la valoración positiva de los procesos vitales, y su distinción respecto de la censura de libertades que se imponía culturalmente a las mujeres que atravesaban su períodos menstruales hasta hace pocas décadas.

\section{La(s) sexualidad(es) en escena}

Elizabeth “Licha” Bernal nació en Resistencia en 1966. Es artista plástica y profesora de grabado, egresada del Instituto Superior Provincial de Bellas Artes del Chaco. En el Instituto Universitario Nacional del Arte (IUNA) cursó la licenciatura en artes visuales y seminarios de posgrado en arte textil. Desde 1985 expone sus obras en muestras colectivas e individuales en su ciudad y Región del Norte argentino. Ejerce como profesora de arte en distintos espacios didácticos de instituciones de nivel secundario y terciario de Resistencia. Su obra plástica se desarrolla básicamente a través del dibujo y el muralismo de manera simultánea, realizando tanto obras de carácter intimista como inmensos murales.

El conjunto de obras elegidas para esta selección, es la correspondiente a la serie "Intrínseco" presentada en 2011. En un primer acercamiento a las obras aparece la celebración de la anatomía femenina como recurso principal para discurrir sobre placer sexual y el dolor físico. La artista expresa sus ideas a través de la representación de imágenes sobre la sexualidad femenina, y deja entrever una perspectiva que está muy distante de la mirada masculina tradicional. La autora belga Luce Irigaray reflexiona sobre las diferencias entre perspectivas sobre la sexualidad en su obra "Ese sexo que no es uno":

"La sexualidad femenina siempre ha sido pensada a partir de parámetros masculinos. De esta suerte, la oposición actividad clitoridiana "viril"/ pasividad vaginal "femenina" de la que habla Freud - y muchos otros... - como etapas, o alternativas, del devenir de una mujer sexualmente "normal", parece sobradamente motivada por la práctica de la sexualidad masculina” (Irigaray, 1977:17). 
Esta perspectiva de género desde la filosofía y el psicoanálisis planteada por Irigaray, encuentra su correspondencia en el imaginario artístico de la historia del arte occidental. A principios de los setenta, los revisionismos de las historiadoras feministas permitieron ver como el arte ha actuado como mecanismo de regulación de conductas en la instalación de estereotipos que reproducían nociones configurantes de la subjetividad, tales como la debilidad y la pasividad de la mujer, su disponibilidad sexual, la relación con la naturaleza (más cercana que la de los varones) o su papel fundamental como esposa y madre (Nochlin, 1991;14-15).

En las obras de Bernal la exhibición del goce sexual femenino (carente de una actitud pasiva) oscila entre una lectura íntima y pública de sus dibujos, debido a que los trabajos varían de escalas proponiendo a los observadores diferentes situaciones: algunas obras deben ser "espiadas" y otras no podrán ser evitadas con la mirada. Intrínseco constituye una provocación entre lo instituido y lo propuesto en relación al placer sexual femenino, la intimidad y el imaginario colectivo esencialista respecto al goce.

Siguiendo a Tubert (2011) sabemos que "en las culturas patriarcales, la regulación del deseo femenino constituye un problema: los deseos femeninos son otros, misteriosos, amenazantes" (Tubert, 2011:32) porque la mujer y específicamente su sexualidad ha sido definida históricamente por contraste respecto a la sexualidad masculina, lo cual no corresponde con las experiencias del colectivo femenino.

Los cuerpos en la obra de Bernal están fragmentados haciendo foco en los sitios de placer femenino e insistiendo en una lectura profunda de su trabajo de dibujo. Los recortes - de importante contenido erótico — presentan ideas sobre las relaciones entre los sexos iguales y diferentes.

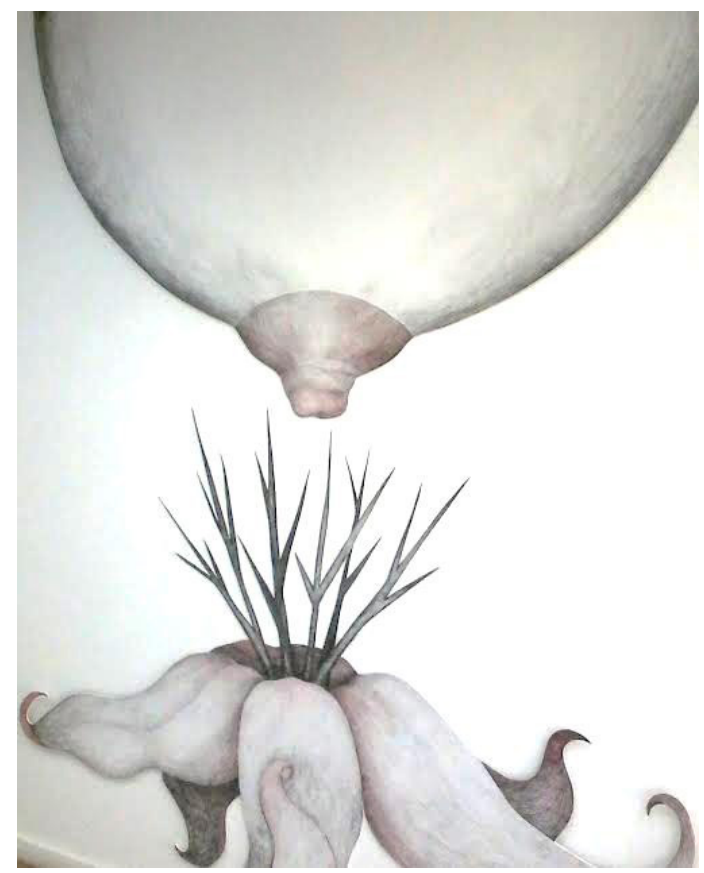

Figura. 3. Licha Bernal "Intrínseco" (2011) Dibujo sobre alto impacto, $150 \times 180 \mathrm{~cm}$. Fotografía de la artista. 
La serie puede ser leída como una inscripción feminista debido a que en la generalidad de la propuesta el placer visual no se instala desde la perspectiva masculina ni hacen foco en la "belleza" de la desnudez femenina. Por otra parte se presenta en contra de la heterodesignación y a favor de la autocomplacencia y el placer de las mujeres.

El título "intrínseco" refiere a la idea de intimidad (en este caso, se entiende que es la femenina) la cual durante una gran parte de la historia ha estado "prohibida" y ha sido señalada como "peligrosa" en discursos falocéntricos.

La perspectiva de Bernal sobre la sexualidad, pareciera estar en la búsqueda de la naturalización del tema a través de compartir sentidos y sentimientos respecto al placer sexual. Ha utilizado el recurso cromático para tensionar al máximo la conexión entre dolor y erotismo, además de emplear constante y metafóricamente flores y espinas para pronunciarse sobre la genitalidad.

Los dibujos de Bernal refieren al placer erótico y la violencia porque han sido temas invisibilizados en la cultura patriarcal. En primer lugar porque la sexualidad de las mujeres ha sido un tabú, pero lo ha sido insistentemente sobre el cuerpo materno, en las adultas mayores o las adolescentes y también hacia las profesiones que ofician de "segundas mamás" como solía llamarse a las maestras. Bernal se aleja con su producción del canon heteronormativo y de la relación entre dos, utilizando la masturbación y lo orgíastico en sus composiciones, situando su obra entre los inestables límites de las categorías de lo artístico, lo pornográfico, lo erótico y lo obsceno en el ámbito de la experiencia estética.

Griselda Pollock —una de las teóricas y críticas feministas de arte más importante de los últmos años - se ha esforzado por divulgar la idea que:

"El feminismo no habla por las mujeres; desafía políticamente aquellas producciones de "mujeres" produciendo contraconstrucciones que no están basadas en una naturaleza, una verdad, una ontología. De este modo, aquello por y desde lo que luchamos está constantemente en formación" (Pollock, 2007: 164).

Licha Bernal está produciendo nuevas formas de pensar la sexualidad femenina. Desde su aporte en el campo artístico puede percibirse un intento de reconfigurar la moral sexual hegemónica poniendo en escena aquello que ha constituido un tabú y que por tanto quedaba reservado al ámbito privado, constituyendo de esta manera una intervención feminista en el escenario artístico local.

\section{Sobre la belleza de lo siniestro}

A Jarumi Nishishinya le cuesta identificar el momento en que comenzó a "ser artista" porque empezó a una edad muy temprana (cerca de los ocho años) y desde entonces ingresó al circuito artístico local con su primera exposición personal a los 16 años en el Museo Provincial de Bellas Artes del Chaco. Como en la actualidad es Licenciada en Psicología, por su doble formación desarrolló proyectos vinculados al arte y la salud mental en el Hospital "Julio Perrando" de Resistencia y el neuro-psiquiatrico "San Francisco" de la ciudad de Corrientes, con el objetivo de trabajar e investigar sobre funciones sociales del arte y su capacidad terapéutica. Su obra artística ha recorrido distintas etapas que ella misma las ha catalogado como la etapa de "la pelirroja" 
a una primera fase que comienza en su adolescencia y sus obras discurren sobre las "incomodidades de una joven con los estereotipos sociales y las determinaciones culturales". Le siguió la etapa "mística" con una serie de pinturas que vinculaba ideas sobre la dualidad de sus orígenes y la búsqueda personal de hacer confluir las religiones heredadas que culminó con la invención de su propia deidad y la conclusión de que "las religiones cierran puertas en lugar de abrirlas". Por último, cuando esa etapa fue superada, surgió el período de "Lo bello y lo siniestro" el cual responde a una fase de trabajo en donde ha logrado la confluencia de sus intereses, artísticos y de la psicología. Esta última etapa de producción es la que se ha seleccionado para la inclusión de su obra en este artículo debido a que la autora recurre a la problemática de la maternidad y lo que ella denomina la "mitificación de la maternidad y el castigo social que representa".

El discurso de la maternidad obligatoria y constitutiva de la cultura occidental ha sido destacado enérgicamente por la tradición judeo-cristiana y reproducido en nuestro país por instituciones del Estado, la ciencia médica y también con mucha fuerza por los medios de comunicación que han prescripto un "deber ser" de la mujer durante una buena parte de la historia. Silvia Tubert pudo advertir que:

"En la mayor parte de las culturas, en la medida que se trata de organizaciones patriarcales, se identifica la feminidad con la maternidad, ya que debido a una capacidad biológica se instala un deber ser, que no respondería a una esencia femenina sino a una representación producida por la cultura" (Tubert,1996:7-8).

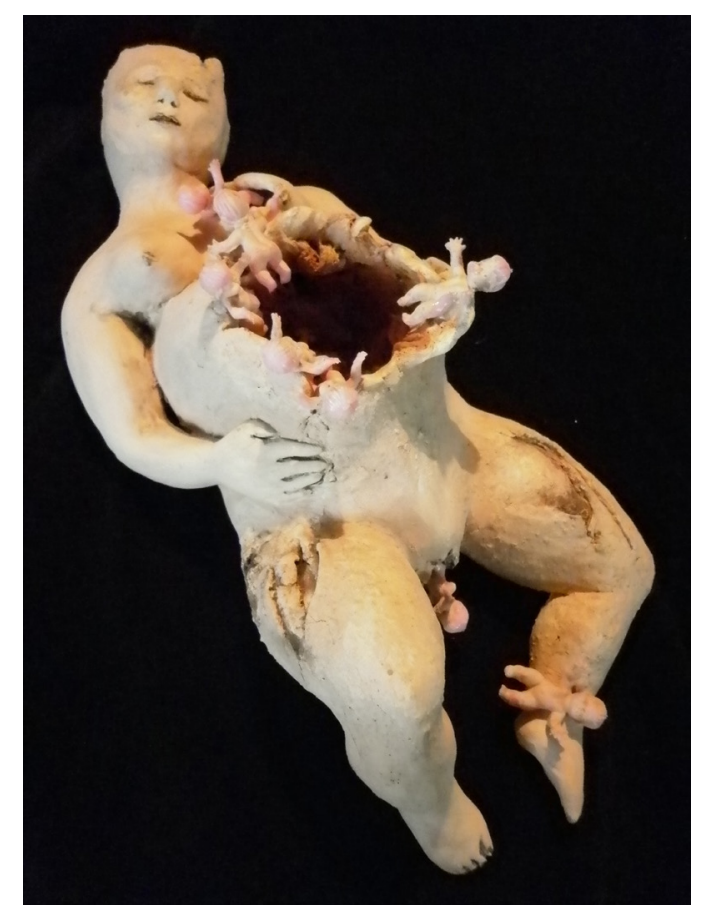

Figura 4. Jarumi Nishishinya "Madraza" (2010) Piezas cerámicas e incrustaciones de juguetes comerciales de plástico, $6 \times 4 \mathrm{~cm}$. Fotografia de la artista 


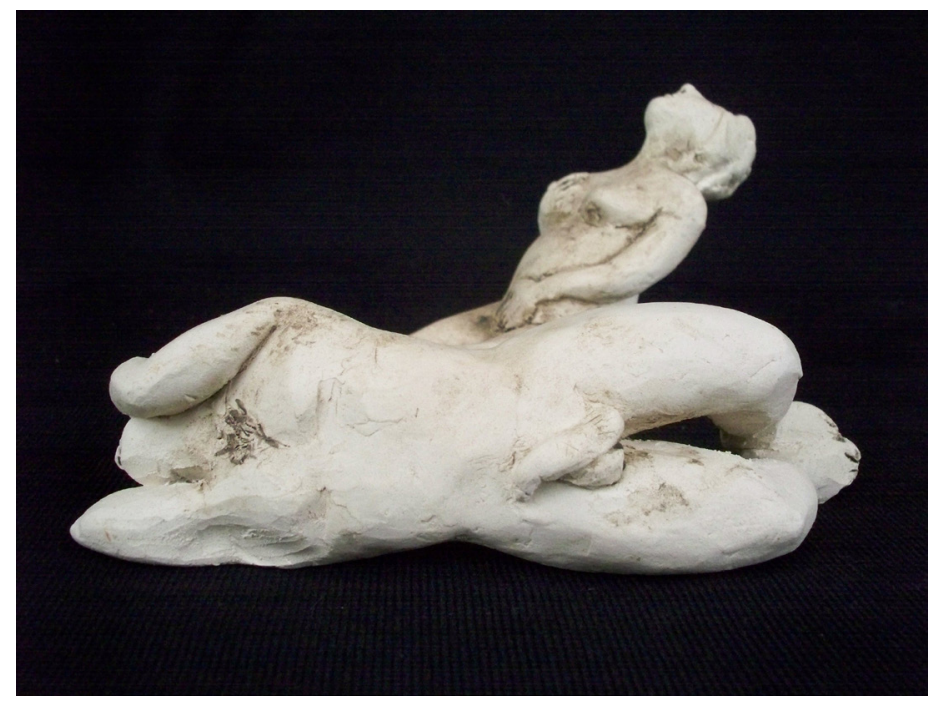

Figura. 5. Jarumi Nishishinya "Sin título" (2010) De la serie "Lo bello y lo siniestro". Piezas cerámicas, $8 \times 4 \mathrm{~cm}$. Fotografía de la artista

Los discursos que inscriben a la mujer como madre y la consecuente esencialización del deseo maternal impiden plantear la diversidad de mujeres como sujetos deseantes reduciendo la sexualidad femenina a su función reproductora.

A través de sus obras, Nishishinya se aproxima a problemáticas de las mujeres como el goce de la sexualidad, la homosexualidad y las representaciones, fantasías e imaginarios sexuales que involucran más que contenidos éticos o religiosos. En sus últimas obras se refirió además a temas complejos como los abusos sexuales, la violencia, la idealización de la maternidad y los vínculos entre madres e hijos. Puede advertirse una atención especial de Nishishinya por estos temas y su vinculación a sujetos invisibilizados y confinados a espacios institucionales de encierro y marginalidad social con quienes trabaja. A partir de su trato cotidiano con personas en dichas condiciones, que pone en práctica sus conocimientos del campo de la psicología haciendo foco en el constante interés humano sobre la sexualidad.

Lo bello y lo siniestro en sus obras no encuentran una escisión y es difícil identificar que imágenes corresponden a cada categoría. Sus mujeres están representadas con arcilla, y de aquellas porciones de tierra, brotan hijos que salen por diferentes partes del cuerpo: orejas, pechos, panza, vagina o piernas. Sus mujeres de arcilla, se tocan disfrutando de los placeres de la masturbación, se frustran ante el deseo insatisfecho por el varón o se deleitan en los encantos del cuerpo propio y el ajeno.

En el discurso del cristianismo sobre la mujer encontramos claramente dos tipologías de mujeres diferenciadas respecto a su sexualidad: Eva y María. La primera encarna el mal de todos los seres humanos, simbolizando la lujuria figurada en cuerpo de mujer y el "peligro" que constituyen para los hombres. La segunda personifica el modelo de madre, a quien las "mujeres de bien" deben seguir aunque biológicamente sean incapaces de imitar. Las representaciones de Nishishinya no eligen entre Eva y María. Sus mujeres son madres y sujetos sexuados, deseantes y concupiscentes. Emancipadas de los preceptos cristianos, nos instan a pensar que las 
mujeres pueden ser una cosa y también su opuesto, evocando el triunfo de los impulsos naturales y dejando atrás las inhibiciones de las cargas morales, quebrando las polaridades y limitaciones que asocian la femineidad con la pasividad. Las figuras no se corresponden con los ideales del cuerpo dominado y disciplinado susceptibles a ser controlados que la Historia del Arte ha transmitido como concepto de creación patriarcal de dominio masculino. Revelan un desborde de matices dionisíacos contrarios a los designios "normales" de la naturaleza y a los de la moral. Expresan abiertamente su sexualidad y deseos, los cuerpos exuberantes no son motivos de vergüenza sino de celebración y las anomalías físicas en primeros planos evidencian la imperfección de la condición humana rechazando la idealización maternal configurada por los discursos hegemónicos propios del patriarcado.

En las obras de Nishishinya se percibe el interés vinculado a su trabajo en psicoanálisis pero también su fuerte compromiso con el ejercicio artístico y social. La artista utilizó diferentes mecanismos para acceder a problemáticas inherentes a las mujeres y cuestionar discursos hegemónicos, tanto como subalternos. Eligió tópicos que involucraron las "miserias" humanas para cargarlos de valoraciones positivas poniendo en juego cuestiones que oscilan entre la angustia y el goce o el placer y el padecimiento, removiendo a través de su obra sentimientos contrapuestos. Sus trabajos combinan lo bello y lo siniestro, como dos categorías para pensar en lo oculto y lo visible, lo familiar y lo extraño o la dicotomía entre ser y parecer. Nishishinya pareciera advertir que la belleza a la que estamos habituados no es la belleza de la cotidianeidad, y por eso intenta imponer ideas poco compatibles con los cánones de representaciones occidentales clásicas, pero presentes en su realidad mundana diaria.

\section{Observaciones finales}

Estas obras tienen en común no sólo su recurrencia a la experiencia corporal condicionada por el género, sino también una insistente búsqueda de poner atención sobre la genitalidad y la(s) sexualidad(es) para tratar cuestiones políticas respecto del cuerpo. González, Bernal y Nishishinya buscan establecer un vínculo con sus espectadores, que va más allá de un intento de complicidad y que se orienta a provocar un encuentro que movilice las ideas que se cimentan sobre bases prefabricadas por la tradición, buscando construir o re-construir ideas a partir de la experiencia personal.

Las contradicciones que se generan al interior de las obras entre "deber ser y realidad", "belleza y repugnancia" o "la violencia y el goce" remiten a condiciones sociales, culturales y económicas muy próximas, para las cuales la perspectiva de género resulta pertinente tener en consideración: un sistema condescendiente emite un discurso que resulta impracticable en la realidad para un gran número de mujeres, lo que pronto se torna agresivo y frustrante.

Barbara Kruger proclamó con su obra "Your body is a batleground" «Tu cuerpo es un campo de batalla» (1989) que el cuerpo era un lugar de lucha. No cualquier cuerpo, el femenino. Allí se dirimen un gran número de aspectos sociales, políticos, económicos, culturales, religiosos e ideológicos los cuales aún se encuentran en el centro de debates éticos y morales en pretensiones de distintas esferas que intentan regular los cuerpos. Desde cánones de belleza a prescripciones sobre la maternidad, los cuerpos están sometidos a presiones que ejercen los ideales que dominan el imaginario social de la feminidad y la construcción cultural del cuerpo de la mujer. La 
influencia ejercida por los medios de comunicación y la publicidad intervienen de modo directo sobre los sujetos dictándoles desde cómo lucir hasta qué comer.

Uno de los aportes valiosos de estas producciones tiene que ver con las connotaciones sociales que éstas traen aparejadas y el contexto en el cual se exhiben, las reacciones que en el público producen ${ }^{3}$. La apropiación de la imagen del cuerpo por parte de estas artistas ha estado atravesada por problemáticas que constituirían un símbolo de su presencia en el espacio público. Espacios simbólicos pero también institucionales conquistados (y por conquistar) devenidos de las luchas con sus pares y ascendientes que en gran número han obstaculizado los caminos para su acceso. Estas artistas son conscientes de las movilizaciones y sensibilidades que afectan debido a que no es su intención realizar obras pasivas y complacientes, sino construir un discurso en el cual la importancia de las representaciones del cuerpo residan en la capacidad de éstas para la construcción y reconstrucción del sujeto femenino y el establecimiento por medio de las diferencias biológicas de una conciencia social respecto a las problemáticas inherentes al género.

En las producciones es posible encontrar cierto malestar vinculado a las obligaciones y tabúes, la imposición de modelos, mandatos y tradiciones que limitan a las mujeres. Por diferentes caminos, indagan en obras significativas de importantes contenidos biológicos y de fuertes cargas emocionales. Por último, las situaciones que deben enfrentar las mujeres en la profesionalización del arte a finales del siglo XX y principios del XXI en esta región, constituye para ellas precisamente un importante ejercicio de resistencia por el que están decididas a luchar. Ante este panorama, el contexto local exige que se extiendan los instrumentos necesarios para que a través de herramientas del campo artístico, cultural y educativo se abran interrogantes que permitan a las artistas pensar su propia obra a través de la visualización de los mecanismos de subjetivación que nos han modelado para deconstruir jerarquías de género aún vigentes.

Por lo dicho hasta aquí las representaciones del cuerpo femenino y la sexualidad se ordenan significativamente diferenciadas dependiendo de si el autor es varón o mujer. Las imágenes corporales utilizadas por las artistas no solo proyectan autorrepresentaciones, sino que constituyen instrumentos políticos e ideológicos y no como meros objetos de goce estético. Resulta curiosa la vigencia de estas reiterativas representaciones - que si bien poseen características diferenciadasconfluyen en ideas acerca de las relaciones de poder y de construcciones subjetivas a partir de la experiencia. Resulta interesante para su estudio y análisis debido a que podría pensarse que los cambios sociales acaecidos en los últimos cincuenta años instalarían una importante distancia en las producciones artísticas, sin embargo aún habría motivos por los cuales algunas artistas siguen tratando los tópicos referidos a la corporalidad y sexualidad en su asociación con ideas que vinculan cuestiones personales y posturas ideológico-políticas.

3 Si bien no se han hecho estudios de público para este trabajo, en los libros de visitas a las exposiciones es usual que los visitantes dejen registros de sus opiniones o mensajes a las artistas. En oportunidades pudieron leerse comentarios agresivos hacia las artistas, en los cuales se cuestionaban además de la obra, su moral y buen gusto. 


\section{Bibliografía}

Amorós Puente, Celia (2000). Feminismo y filosofía, Madrid: Síntesis.

(ed.) (2000). Mujeres e imaginarios de la globalización. Reflexiones para una agenda teórica global del feminismo. Rosario: Homosapiens.

Arqueros, Guadalupe y Geat, Andrea (2011). El cuerpo transparente de María Victoria González. Discursos estéticos de género localizados en manifestaciones de arte textil. En Actas de XXXII Encuentro de Geohistoria Regional, Resistencia: Instituto de Investigaciones Geohistóricas.

Bach A.M., Gianella A., Femenías María Luisa, Roulet, Margarita y Santa Cruz M.I. (1994). Mujeres y filosofía. Teoría filosófica de género. Buenos Aires: Centro Editor de América Latina. Tomo II.

De Lauretis, Teresa (1991). La tecnología del género. En El género en perspectiva, México: UAM.

Deepwell, Katy (ed.) (1998). Nueva crítica feminista de arte. Estrategias críticas. Madrid: Cátedra.

Ecker, Gisela (ed.) (1986). Estética feminista. Barcelona: Icaria.

Femenías, María Luisa; Gianella, Alicia; Santa Cruz, María Isabel y otras. (1994). Mujeres y Filosofía. Teoría filosófica de género. "Para comprender el género: Precisiones epistemológicas". Tomo I, Buenos Aires: Centro Editor de America Latina.

Fernández Valencia, Antonia y López Fernández Cao, Marián (Coord.) (2011). Contar con el cuerpo: Construcciones de la identidad femenina. Madrid: Fundamentos.

Giunta,Andrea (2011). Escribir las imágenes. Ensayos sobre arte argentino ylatinoamericano. Buenos Aires: Siglo veintiuno.

Gutiérrez Viñuales, Rodrigo (dir.) (2005). Arte latinoamericano del Siglo XX. Otras historias de la historia. Zaragoza: Prensas universitarias de Zaragoza.

Irigaray, Luce (2009). Ese sexo que no es uno. Madrid: Akal.

Izquierdo, Ma. Jesús (1998). El malestar en la desigualdad. Madrid: Cátedra.

López Fernández Cao, Marián (Coord.) (2000). Creación artística y mujeres. Recuperar la memoria. Madrid: Narcea.

Mayayo, Patricia (2007). Historias de mujeres, historias del arte. Madrid: Cátedra.

Nead, Lynda (1998). El desnudo femenino. Arte, obscenidad y sexualidad. Madrid: Tecnos.

Nochlin, Linda (1971). ¿Por qué no han existido grandes artistas mujeres? En: Cordero Reiman, Karen y Sáenz, Inda, (2007) Crítica feminista en la teoría e historia del arte. Ciudad de México: Universidad Iberoamericana.

Nochlin, Linda (1991). Women, art and power. En N. Bryson, M.A. Holly y K. Moxey, Visual Theory. Painting and interpretation. New York; Harper-Collins.

Oliveras, Elena. (2008). Cuestiones de arte contemporáneo. Hacia un nuevo espectador en el Siglo XXI. Buenos Aires: Emecé.

Palermo, Zulma (Coord.) (2006). Cuerpo(s) de mujer: representación simbólica y crítica cultural. Córdoba: Ferreyra editor.

Panofsky, Erwin (1987). El significado de las artes visuales, Madrid; Alianza/Forma.

Prada, Juan L. M. (2000). Arte feminista y esencialismo. En: López Fernández Cao, Marián. (2000). Creación artística y mujeres. Recuperar la memoria (165-176). Madrid: Narcea.

Robinson, Hilary. (1995). Más allá de los límites: feminidad, cuerpo y representación. En: Deepwell, Katy (ed.) (1998) Nueva crítica feminista de arte. Estrategias críticas. (241255). Madrid: Cátedra. 
Rosa, María L. (2014). Legados de libertad. El arte feminista en la efervescencia democrática. Buenos Aires: Biblos.

Tubert, Silvia (ed.) (1996). Figuras de la madre. Madrid: Cátedra.

- (2011). Desórdenes del cuerpo. El retorno de lo excluido. En:

Fernández Valencia, Antonia y López Fernández Cao, Marián (Coord.) (2011) Contar con el cuerpo: Construcciones de la identidad femenina. (15-33). Madrid: Fundamentos. 